\title{
Design and Implementation of Supermarket Personnel Management System Based On Java
}

\author{
Shiyong Zheng ${ }^{1, \text { a }}$, Qin Deze ${ }^{1}$, Qiang Zhu ${ }^{2, b}$, Biqing Li $^{3}$ \\ ${ }^{1}$ School of Computer Science and Information Engineering, Hezhou University, Hezhou Guangxi \\ 542899, China \\ ${ }^{2}$ College of information \& business, Zhongyuan University of Technology, Zhengzhou Henan 450007 , \\ China \\ ${ }^{3}$ School of Mechanical and Electronic Engineering, Hezhou University, Hezhou Guangxi 542899, \\ China \\ ajanliful@163.com, b229292710@qq.com
}

Keywords: Personnel management,MVC Pattern, Struts2 Framework, Java.

\begin{abstract}
In order to improve the efficiency of the supermarket personnel management work, the text designs a supermarket personnel management system, The function of this system include employee entry, staff mobility, personnel management and so on. The system uses the Java programming language, object-oriented-oriented interface design ideas for the section, and the layered architecture of the Struts2 framework and MVC pattern.
\end{abstract}

\section{Introduction}

Using the paper material as information management is a traditional way that various enterprises such as supermarkets often apply it to personnel management, but as the development of economic globalization, it is hard to meet the requirements of supermarkets' personnel management. The combination of the supermarket personnel management system and the modern Internet techniques can realize the informatization and modernization of supermarket's personnel management.

It can apply the technologies such as electronic and network to establish the informational personnel management of supermarket, in order to achieve the characters as large memory, high security, long service time, fast search and low cost. These advantages have benefits to reduce the company's cost of supervising staff and the burden of managers, they also make employee information convenient to update, maintain and query, increasing the reliability of the data.

\section{Requirement Analyses}

\subsection{Function requirement}

Supermarket personnel management system is used for the staff and personnel department of supermarket; it might realize the operations such as query, modification, and deletion and enter employee information. It also allows general staff to evaluate their department manager anonymously, and the administrator to release information of cultivating in this system.

The modular structure chart of system function as follow:

\subsection{Performance requirement}

(1) Real-time: the staff can see the latest personnel information and assessing information from others to oneself, and the training information, department information which are published by enterprise in real time.

(2) Flexibility: the application is written in java and has the feature of across-platform, and browser is the client of $\mathrm{B} / \mathrm{S}$ pattern, which is simple and convenient for user to use the management system in different operating systems.

\subsection{Hardware requirement}

Writing additional client is no needed because this project uses the B/S pattern. It only requires a computer as server, the user of supermarket personnel management system only need to access by a 
browser. So the hardware is undemanding, and dominant hardware is enough, for example, CPU main frequency is over $1.6 \mathrm{G}$, memory is $1 \mathrm{G}$ and upwards, then hard disk is $100 \mathrm{G}$ and higher. Operating system requires: windows XP or windows2000 and above; database software demand: MySQL or Oracle database; server software demand: Tomcat 6.0.

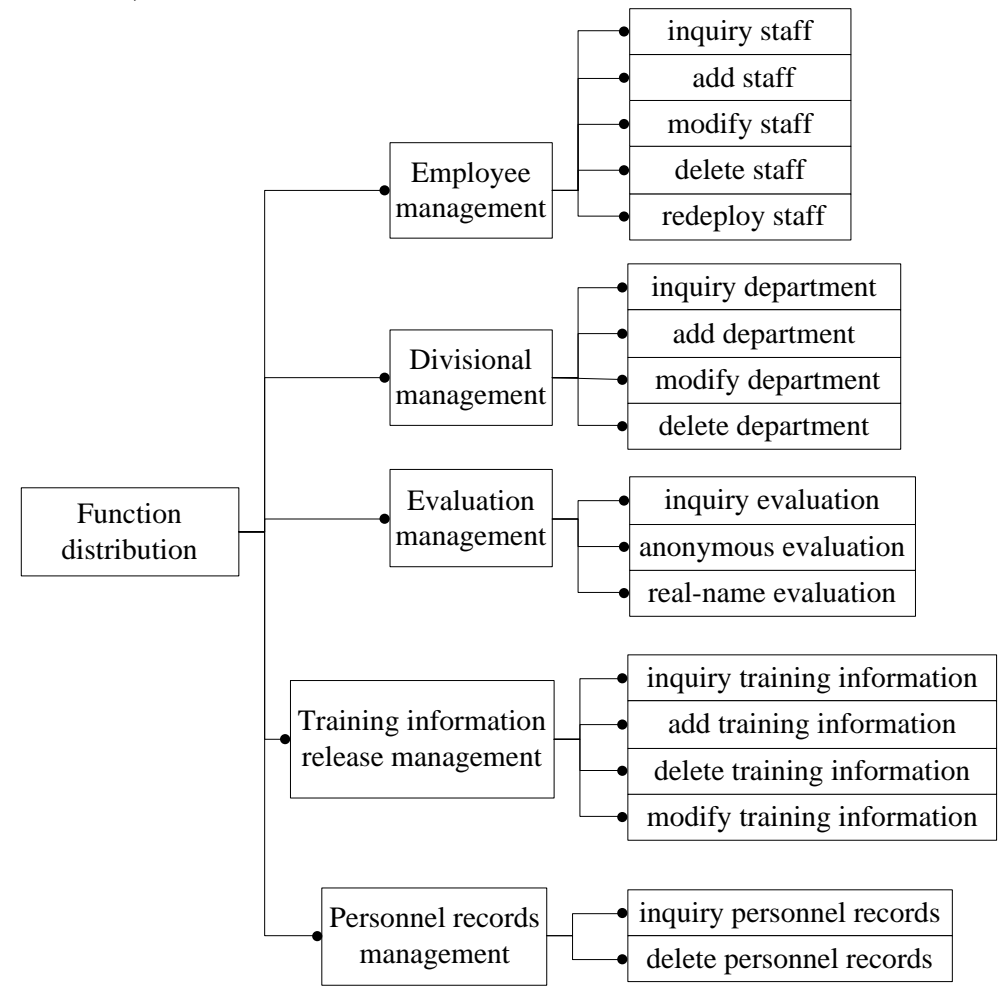

Fig. 1 modular structure chart of system function

\section{Overall designs}

\subsection{Operation flowDiagram}

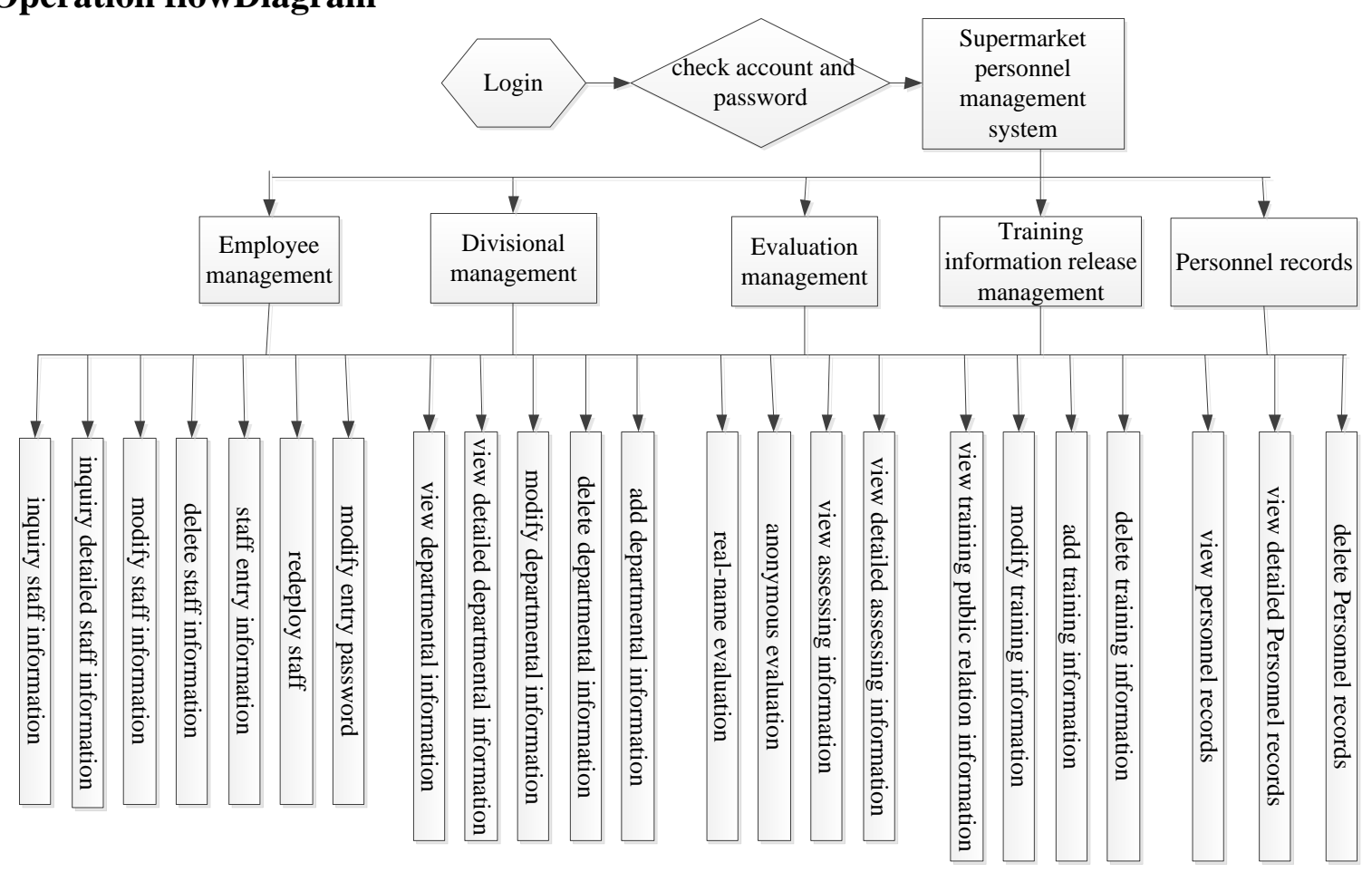

Fig. 2 Operation flow chart 


\subsection{Data Flow Diagram}
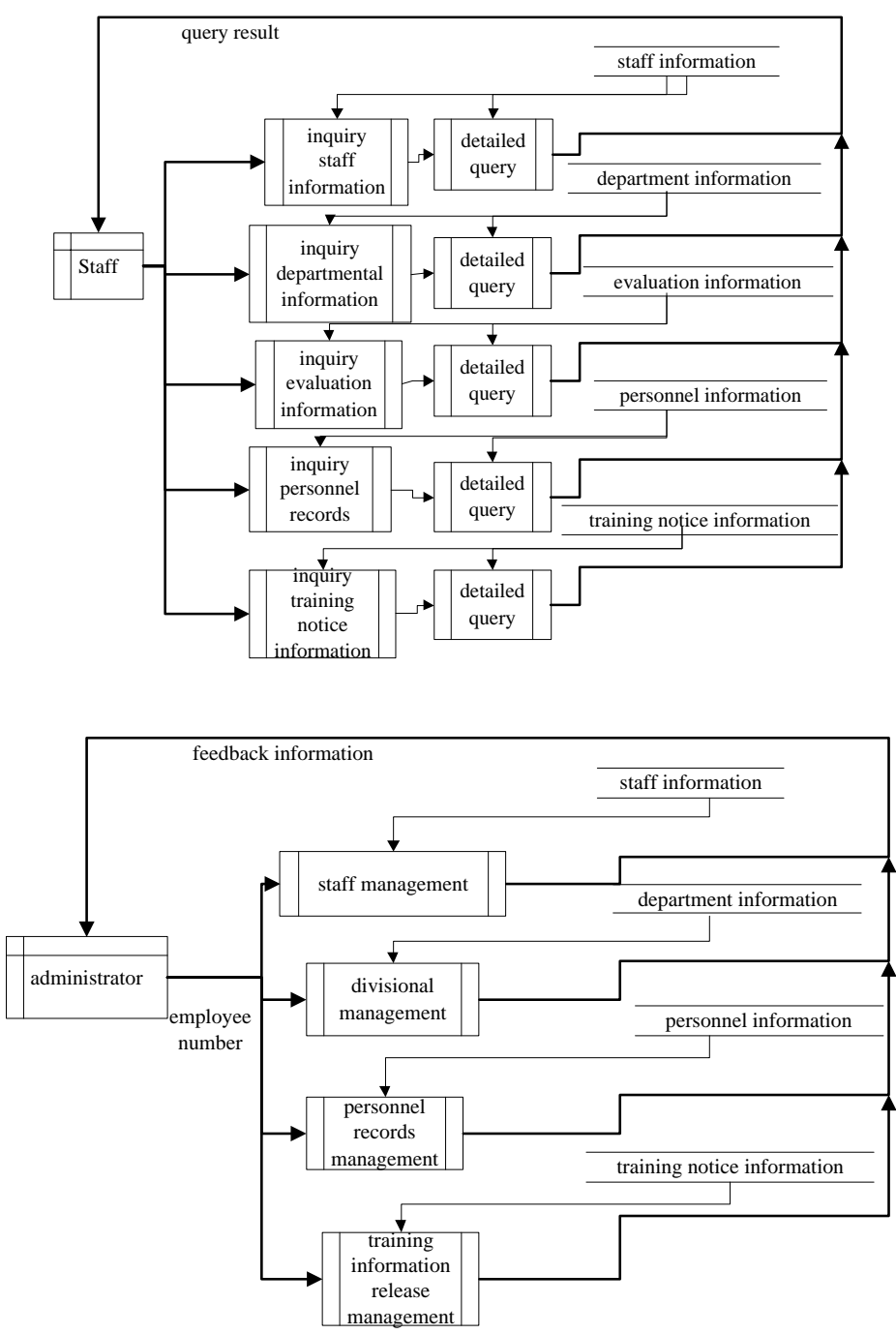

Fig. 3 data flowchart

Some sentences of creating table:

Create table tb_dept

(dt_idint primary key auto_increment,

dt_namevarchar(50),

dt_createTimevarchar(30),

dt_bztext

)ENGINE=InnoDB DEFAULT CHARSET=gbk COMMENT='department table';

\section{4. detailed design}

Using the module of redeploying staff as an example, this function is mainly applied to staff transfer. When the employee needs to be transferred, the administrator (staff of personnel department) can enter the system of "staff management" to transfer employee, and then chooses the employee in staff list, clicking the "transfer". This moment the page of staff transfer will appear, and the operations such as "employee promoted" and "exchange employee department" can be achieved in this page.

In the operation of "employee promoted", people can check whether there had been another manager in this department when the employee is promoted as manager. It will be fail if there is another manager, and then go to related interface of error. Otherwise the operation succeeds and this operational information will be recorded in personnel records table, and it will jump to the related interface.

Flowchart of staff transfer as follow: 


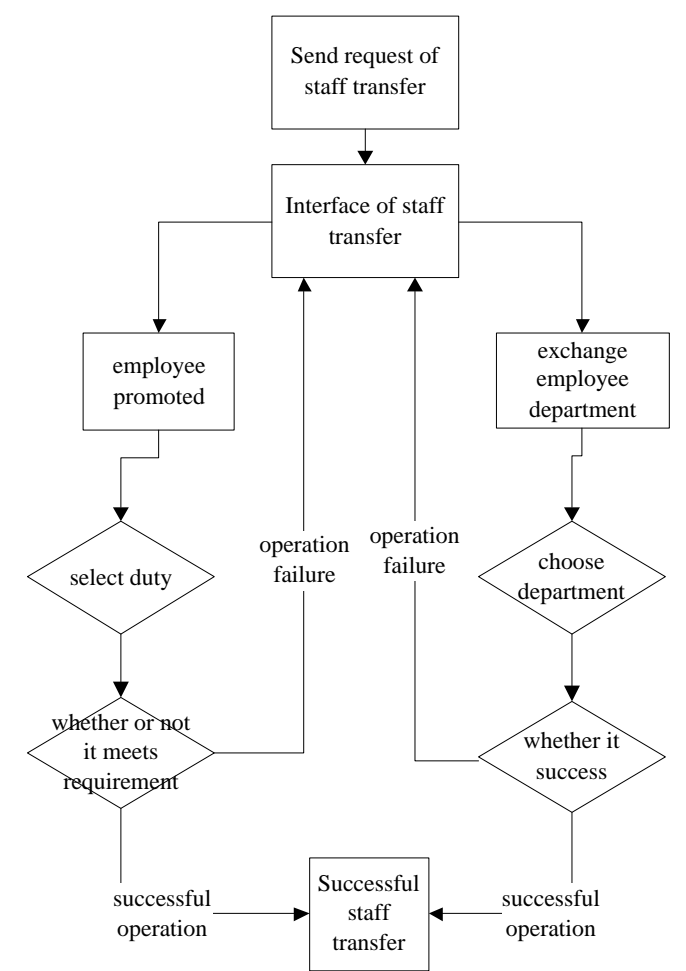

Fig. 5 Flowchart of staff transfer

\section{5. software testing}

According to the test plan, the module testing conduct first before coming to system integration test. The test part omitted here.

\section{Summary}

This system adopts Struts 2 as the underlying framework, and its layered architecture uses the B/S and MVC pattern. Meanwhile the data link combines JDBC with dbcp. The main functions of the whole management system have basically realized. But there is shortcoming, such as the UI interface may not concise beauty enough. However, it's happens without effecting to the purpose of the design.

This work is supported by Guangxi science and technology development projects, Tourism security key technology and development of new products research (No 1355009-9);Scientific research project of Guangxi colleges and universities "Application research on data migration technology based on XML and middleware" (No 2013LX140); Scientific research project of school level "The intelligent home system Implementation Research based on the Internet of Things technology” (No 2014YBZK10);

\section{References}

[1]. [U.S] written by Russel Dyer, translated by Li Hongjun, Li Dongmei. MySQL in a Nutshell, Second Edition,China Machine Press, 2011.9, p. 221-225.

[2]. LiGang.LightweightJava EE Enterprise Application Field.Publishing House of Electronics Industry, 2013, p. 31-36.

[3]. Linda Sun. Java Object Oriented Programming [M]. Beijing: Publishing House of Electronics Industry, 2013

[4]. Zheng Shiyong, Li Biqing. Design and Implementation of the LAN Chat System Based on MFC Technology [J].Journal of Hezhou University, Vol.4(2013) p. 175-178. 